\title{
Inhibition of granzyme B activity blocks inflammation induced by lipopolysaccharide through regulation of endoplasmic reticulum stress signaling in NK92 cells
}

\author{
LEI WANG $^{1}$, SHAOWEI JIANG ${ }^{1}$, LING XIAO $^{1}$, LIN CHEN $^{1}$, YANYAN ZHANG $^{1}$ and JING TONG ${ }^{2}$ \\ ${ }^{1}$ Department of Clinical Immunology, Institute of Laboratory Medicine, \\ Hubei University of Chinese Medicine, Wuhan, Hubei 430065; ${ }^{2}$ Aristogenesis Genetic Laboratory, \\ Wuhan Children's Hospital (Wuhan Maternal and Child Healthcare Hospital), Tongji Medical College, \\ Huazhong University of Science and Technology, Wuhan, Hubei 430074, P.R. China
}

Received July 20, 2017; Accepted December 8, 2017

DOI: $10.3892 / \mathrm{mmr} .2018 .8995$

\begin{abstract}
Granzyme B $(\mathrm{GrB})$ is a serine protease that is expressed in the lytic granules of natural killer (NK) cells and cytotoxic T lymphocytes (CTL), and which has been widely reported to serve a crucial role for target cell apoptosis. GrB may serve a non-cytotoxic role in inflammation, but the evidence remains unclear. The present study aimed to establish an inflammatory cell model by using NK92 cells stimulated with lipopolysaccharide (LPS) to investigate whether GrB was involved in the development of inflammation. The extracellular levels of tumor necrosis factor- $\alpha$ (TNF- $\alpha$ ), interleukin-1 $\beta$ (IL-1 $\beta$ ) and GrB were examined by ELISA, and it was demonstrated that LPS treatment increased the extracellular levels of TNF- $\alpha$, IL- $1 \beta$ and GrB, and these increased expression levels were inhibited by pretreatment with the GrB inhibitor serpin A3N (SA3N). The protein expression levels of glucose-regulated protein 78 (GRP78), $\mathrm{C} / \mathrm{EBP}$ homologous protein (CHOP), nuclear factor $-\kappa \mathrm{B}$ $(\mathrm{NF}-\kappa \mathrm{B})$, inhibitor of $\mathrm{NF}-\kappa \mathrm{B}(\mathrm{I} \kappa \mathrm{B} \alpha)$ and $\mathrm{GrB}$ were examined by western blot analysis. The results demonstrated that LPS stimulation increased the expression levels of GRP78, CHOP, $\mathrm{NF}-\kappa \mathrm{B}$ and $\mathrm{GrB}$, and decreased the expression of $\mathrm{I} \kappa \mathrm{B} \alpha$, and these changes were inhibited by $\mathrm{SA} 3 \mathrm{~N}$, which indicated that inhibition of GrB activity may suppress endoplasmic reticulum (ER) stress signaling. Therefore, it was suggested that GrB may be a potential pro-inflammatory factor, and inhibition
\end{abstract}

Correspondence to: Dr Jing Tong, Aristogenesis Genetic Laboratory, Wuhan Children's Hospital (Wuhan Maternal and Child Healthcare Hospital), Tongji Medical College, Huazhong University of Science and Technology, 100 Hongkong Road, Jiang'an, Wuhan, Hubei 430074, P.R. China

E-mail: lifelei123@sina.com

Key words: granzyme B, inflammation, endoplasmic reticulum stress, natural killer-92 cells of GrB activity may aid the prevention of the development of inflammation by suppressing ER stress signaling.

\section{Introduction}

Natural killer (NK) cells and cytotoxic T lymphocytes (CTLs) provide crucial defense against virus-infected cells and tumor cells; NK cells and CTLs target tumor cells and induce apoptosis (1). Granzyme B ( GrB) belongs to a family of serine proteases that are expressed in the granules of activated CTLs and $\mathrm{NK}$ cells that induce apoptosis $(2,3)$. GrB is also expressed in non-lymphoid lineage cells, including chondrocytes, neutrophils, keratinocytes and macrophages (4). It has been reported that the intracellular serpin proteinase inhibitor 9 may protect monocytes and macrophages from misdirected $\mathrm{GrB}$ in the lipopolysaccharide (LPS)-induced inflammatory process (5). GrB is considered a 'natural born killer' that functions at multiple points, including directing proteolytic processing and activation of procaspase- 3 and -7 , to initiate the death of the harmful target cells, including allogeneic, virus-infected and tumor cells (6). GrB directly targets caspase-3 and initiates the caspase cascade, leading to DNA fragmentation and apoptosis. Alternately, in the absence of caspase activity, GrB may still be able to initiate mitochondrial events through the cleavage of the B-cell lymphoma 2 homology domain 3-interacting domain death agonist protein (7), which is important to cell death and is susceptible to proteolytic cleavage by $\mathrm{GrB}$ as well as caspases, calpains and cathepsins (8). A recent report suggested that GrB may also possess non-cytotoxic roles under inflammatory circumstances as well as possible functions in the extracellular space (9). In addition, previous studies have reported that GrA and GrB may influence the production of pro-inflammatory cytokines; however, the molecular targets of these proteases in inflammation remain unknown $(10,11)$. Whether GrB is involved in and promotes the development of inflammation also remains to be elucidated.

LPS is a component of the Gram-negative bacteria cell wall that is known to induce inflammation in a number of physiological and experimental settings. A previous study reported that inhibition of endoplasmic reticulum (ER) stress 
alleviated LPS-induced lung inflammation through modulation of the nuclear factor- $\kappa \mathrm{B}(\mathrm{NF}-\kappa \mathrm{B})$ signaling pathway (12). Serine protease inhibitor $\mathrm{A} 3 \mathrm{~N}$ (serpin $\mathrm{A} 3 \mathrm{~N}$; SA3N) is an extracellular inhibitor of $\mathrm{GrB}$ that has been demonstrated to possess multiple biological functions, including the attenuation of muscular dystrophy in mice (13), neuropathic pain (14) and GrB-mediated decorin cleavage and rupture (15); it also induces neuroprotection in vitro and in vivo (16).

The present study established an inflammatory cell model by using NK92 cells stimulated with LPS, and demonstrated that the LPS-induced inflammatory response was prevented by the inhibition of GrB activity.

\section{Materials and methods}

Chemicals. LPS (Escherichia coli 0111:B4) was purchased from Sigma-Aldrich (Merck KGaA, Darmstadt, Germany); $\alpha$-minimum essential medium (MEM) and antibodies against glucose-regulated protein 78 (GRP78; cat. no. sc-376768), C/EBP homologous protein (CHOP; cat. no. sc-4066) and $\beta$-actin (cat. no. sc-8432) were purchased from Santa Cruz Biotechnology, Inc. (Dallas, TX, USA). Antibodies against GrB (cat. no. 4275S), NF- $\kappa$ B (cat. no. 8242S) and inhibitor

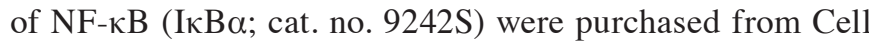
Signaling Technology, Inc. (Danvers, MA, USA).

Cell culture. NK92 cells were supplied from Kunming Institute of Zoology (Kunming, China; the human NK92 cell were established from a donor who suffered from malignant non-Hodgkin's lymphoma and who gave written informed consent). NK92 cells were maintained in $\alpha$-MEM medium with 5\% heat-inactivated fetal bovine serum (FBS) and $10 \%$ heat-inactivated fetal horse serum (both Thermo Fisher Scientific, Inc., Waltham, MA, USA) and antibiotics (100 U/ml penicillin and $100 \mu \mathrm{g} / \mathrm{ml}$ streptomycin) at $37^{\circ} \mathrm{C}$ in a humidified $5 \% \mathrm{CO}_{2}$ atmosphere.

\section{LPS-induced inflammation}

Concentration dependence of LPS. NK92 cells in logarithmic growth phase were incubated in 6-well culture plates and divided into 6 groups, each treated with 1, 10, 50, 100, and $500 \mathrm{ng} / \mathrm{ml}$ LPS, along with an untreated control group. Following medium exchange, $100 \mu \mathrm{l}$ of the different concentrations of LPS were added to the 6 different LPS treatment groups, and $100 \mu \mathrm{l} \alpha$-MEM medium containing 5\% heat-inactivated FBS, $10 \%$ heat-inactivated fetal horse serum and antibiotics (100 U/ml penicillin and $100 \mu \mathrm{g} / \mathrm{ml}$ streptomycin) were added to the control group. The cells were then incubated at $37^{\circ} \mathrm{C}$ in a humidified $5 \% \mathrm{CO}_{2}$ atmosphere for $24 \mathrm{~h}$. The cell culture medium was collected and precipitated by centrifugation for $5 \mathrm{~min}\left(750 \mathrm{x} \mathrm{g}, 4^{\circ} \mathrm{C}\right)$ and the clear supernatant extract was analyzed using ELISA. Experiments were performed in triplicate.

Time dependence of LPS. According to the optimal concentration determined by the previous LPS concentration dependence test, $100 \mathrm{ng} / \mathrm{ml}$ LPS was added to every test group. NK92 cells in logarithmic growth phase were incubated in 6-well culture plates and divided into 5 groups, which were incubated with LPS for 0 (control), 12, 24, 48 or $72 \mathrm{~h}$. The cell culture medium was collected and precipitated by centrifugation for 5 min $\left(750 \times \mathrm{g}, 4^{\circ} \mathrm{C}\right)$ and the clear supernatant extract analyzed using ELISA. Experiments were performed in triplicate.

Role of SA3N on LPS-induced inflammation. NK92 cells in logarithmic growth phase were incubated in 6-well culture plates and divided into 4 groups: control, LPS, LPS + SA3N (GeneCopoeia, Inc., Rockville, MD, USA) and SA3N groups. The cells were treated with SA3N $(20 \mu \mathrm{M})$ for $30 \mathrm{~min}$ at $37^{\circ} \mathrm{C}$ followed by stimulation with $100 \mathrm{ng} / \mathrm{ml}$ LPS for $24 \mathrm{~h}$ at $37^{\circ} \mathrm{C}$. Cell culture medium was collected and precipitated by centrifugation for $5 \mathrm{~min}\left(750 \mathrm{x} \mathrm{g}, 4^{\circ} \mathrm{C}\right)$ the clear supernatant extract was analyzed using ELISA, and the sedimented cells were analyzed by western blotting. Experiments were performed in triplicate.

ELISA analysis. The levels of TNF- $\alpha$, IL- $\beta$ and GrB in the clear supernatant extract were quantified using Quantikine ELISA kits (R\&D Systems, Inc., Minneapolis, MN, USA; TNF- $\alpha$, cat. no. DTA00C; IL- $\beta$, cat. no. DLB50; GrB, cat. no. DY2906-05), according to the manufacturer's protocols. Plates were read in an ELISA reader (Bio-Rad Laboratories, Inc., Hercules, CA, USA) at $450 \mathrm{~nm}$. The values obtained were plotted onto the standard plot prepared by using serial dilutions of the standard provided with the kit and TNF- $\alpha$, IL- $\beta$ and $\mathrm{GrB}$ concentrations were calculated.

Western blot analysis. Cells were plated in 6-well plates at a density of $1 \times 10^{5}$ cells/well. Total protein was extracted using lysis buffer and incubated on ice for $1 \mathrm{~h}$. Protein lysates were prepared using a solubilizing solution $[20 \mathrm{mM}$ Tris- $\mathrm{HCl}$ (pH 7.4), $150 \mathrm{mM} \mathrm{NaCl}, 1 \%$ NP-40, 1 mM EDTA, 1 mM phenylmethanesulfonyl fluoride, $1 \mathrm{mM}$ ethylene-bis(oxyethyl enenitrilo)-tetraacetic acid, 1\% Triton X-100, $2.5 \mathrm{mM}$ sodium pyrophosphate, $1 \mathrm{mM} \mathrm{Na}_{3} \mathrm{VO}_{4}, 1 \mathrm{mM} \beta$-glycerol phosphate, and $1 \mathrm{mg} / \mathrm{ml}$ leupeptin]. Protein concentrations were determined using a Bio-Rad protein assay reagent (Bio-Rad Laboratories, Inc.). Samples were separated on 12\% SDS-PAGE and transferred to a polyvinylidene difluoride membrane (EMD Millipore, Billerica, MA, USA). The membrane was rinsed with PBS and nonspecific sites were blocked by incubating the membrane with blocking buffer (PBS $+0.1 \%$ Tween-20, containing $10 \%$ nonfat milk) overnight at $4{ }^{\circ} \mathrm{C}$ or for $2 \mathrm{~h}$ at room temperature. Membranes were subsequently incubated with primary antibodies to GrB $(1: 1,500)$, GRP78 $(1: 1,000)$,

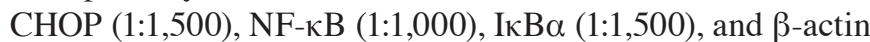
$(1: 1,500)$ for $1 \mathrm{~h}$ at room temperature, followed by incubation with horseradish peroxidase-conjugated anti-mouse (1:10,000; cat. no. MA5-16308) or anti-rabbit (1:10,000; cat. no. 42-6600) immunoglobulin G (KPL, Inc., Gaithersburg, MD, USA) for $1 \mathrm{~h}$ at room temperature. Protein bands were visualized using an ECL Western Blot Detection kit (EMD Millipore). ImageJ V1.8.0 software (National Institutes of Health, Bethesda, MD, USA) was used for the densitometric analysis. All protein bands are normalized to $\beta$-actin. Three independent experiments were performed.

Statistical analysis. Data were analyzed by using SPSS software 16.0 (SPSS, Inc., Chicago, IL, USA) and were expressed as the mean \pm standard error of the mean. One-way analysis of 
A

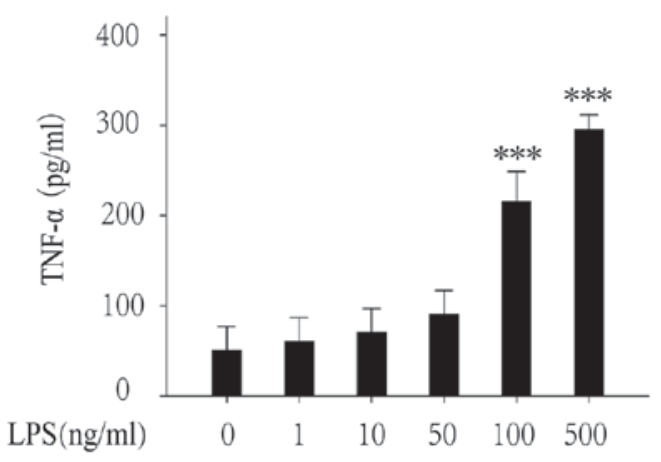

C



B

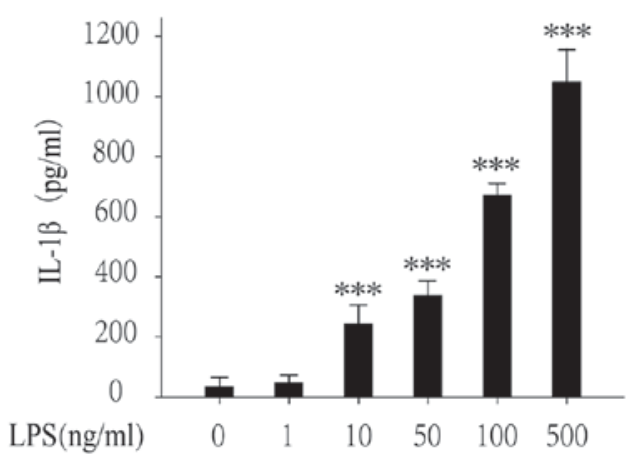

D

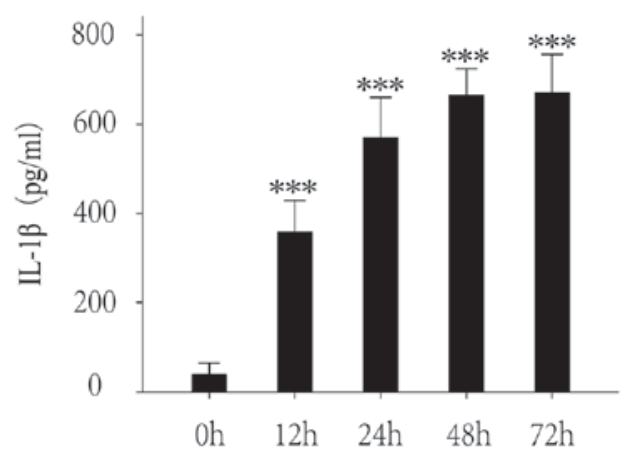

Figure 1. LPS-induced inflammatory response in NK92 cells. (A) LPS treatment significantly increased the extracellular levels of TNF- $\alpha$ at $100 \mathrm{and} 500 \mathrm{ng} / \mathrm{ml}$ following incubation for $24 \mathrm{~h}$. (B) LPS significantly increased the extracellular levels of IL-1 $\beta$ at 10, 50, $100 \mathrm{and} 500 \mathrm{ng} / \mathrm{ml}$ following incubation for $24 \mathrm{~h}$. (C and D) LPS significantly increased the extracellular levels of (C) TNF- $\alpha$ and (D) IL- $\beta$ at $100 \mathrm{ng} / \mathrm{ml}$ following incubation for $12,24,48$ and $72 \mathrm{~h} .{ }^{* * *} \mathrm{P}<0.001$ vs. $0 \mathrm{ng} / \mathrm{ml}$ (and 0 h) untreated control cells. IL-1 $\beta$, interleukin-1 $\beta$; LPS, lipopolysaccharide; NK, natural killer; TNF- $\alpha$, tumor necrosis factor- $\alpha$.

variance followed by a Bonferroni post hoc multiple comparison test was used to compare control and treated groups. $\mathrm{P}<0.05$ was considered to indicate a statistically significant difference.

\section{Results}

LPS-induced inflammatory response in NK92 cells. TNF- $\alpha$ and IL-1 $\beta$ are key cytokines involved in inflammation. The extracellular levels of TNF- $\alpha$ and IL-1 $\beta$ were investigated by ELISA following LPS treatment (1, 10, 50, 100 and $500 \mathrm{ng} / \mathrm{ml}$ ) for $24 \mathrm{~h}$. The results demonstrated that $100 \mathrm{ng} / \mathrm{mg}$ LPS significantly increased the levels of TNF- $\alpha$ (Fig. 1A) and IL-1 $\beta$ (Fig. 1B). The extracellular levels of TNF- $\alpha$ and IL-1 $\beta$ following LPS treatment $(100 \mathrm{ng} / \mathrm{ml})$ for various times $(0,12$, 24,48 and $72 \mathrm{~h}$ ) were subsequently investigated. The results demonstrated that LPS significantly increased the levels of TNF- $\alpha$ (Fig. 1C) and IL-1 $\beta$ (Fig. 1D) following treatment for $12 \mathrm{~h}$, and the levels become stable at $24 \mathrm{~h}$. Thus, $100 \mathrm{ng} / \mathrm{ml}$ for $24 \mathrm{~h}$ was set as the best condition for the following experiments.

SA3N pretreatment prevents the expression and exocytosis of $G r B$ by LPS. The expression of GrB was examined by western blotting and the results demonstrated that LPS increased the expression of $\mathrm{GrB}$, whereas SA3N $(20 \mu \mathrm{M})$ pretreatment suppressed the increase by LPS (Fig. 2A). In Fig. 2A, the bands that appear above GrB may be a larger fragment of $\mathrm{GrB}$ or may also be a nonspecific binding, as the active $\mathrm{GrB}$ is derived from the precursor GrB by deglycosylation. Generally, the molecular weight of the precursor $\mathrm{GrB}$ is $35 \mathrm{kDa}$, and the active $\mathrm{GrB}$ is $32 \mathrm{kDa}$. The extracellular levels of $\mathrm{GrB}$ were examined by ELISA and the results demonstrated that LPS increased the extracellular levels of GrB, whereas SA3N pretreatment suppressed the increase by LPS stimulation (Fig. 2B).

$S A 3 N$ pretreatment prevents the exocytosis of TNF- $\alpha$ and $I L-1 \beta$ induced by LPS. The extracellular levels of TNF- $\alpha$ and IL-1 $\beta$ were examined by ELISA. The results demonstrated that LPS increased the extracellular levels of TNF- $\alpha$ (Fig. 3A) and IL-1 $\beta$ (Fig. 3B), whereas SA3N pretreatment suppressed the increases by LPS treatment. The results indicated that reduction of GrB activity may contribute to alleviate the LPS-induced inflammatory response.

SA3N pretreatment prevents the LPS-induced changes in expression levels of GRP78,CHOP, NF- $\kappa B$ and $I \kappa B \alpha$ proteins. GRP78, CHOP, NF- $\kappa \mathrm{B}$ and $\mathrm{I} \kappa \mathrm{B} \alpha$ were involved in LPS-induced ER stress $(12,17)$. It has been demonstrated that inhibition of ER mediated by $\mathrm{NF}-\kappa \mathrm{B}$ pathway may alleviate LPS-induced lung inflammation (12).Thus, the NF- $\mathrm{B}$ pathway was examined. The western blotting results demonstrated that LPS stimulation increased the expression levels of GRP78, 
A



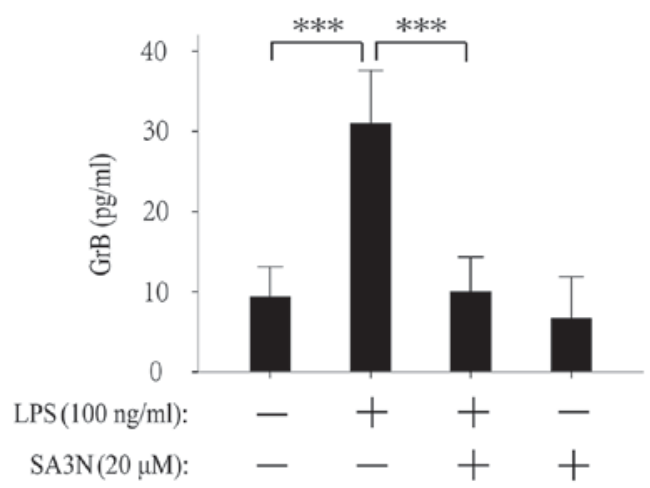

Figure 2. Role of SA3N pretreatment on the expression and exocytosis of GrB by LPS. (A) LPS treatment increased the protein expression level of GrB, whereas SA3N $(20 \mu \mathrm{M})$ pretreatment suppressed this LPS-induced increase. (B) LPS increased the extracellular levels of GrB, and SA3N pretreatment suppressed the increase by LPS. ${ }^{* * *} \mathrm{P}<0.001$. GrB, granzyme B; LPS, lipopolysaccharide; SA3N, serpin A3N.


Figure 3. Role of SA3N pretreatment on the LPS-induced exocytosis of TNF- $\alpha$ and IL-1 $\beta$. (A and B) LPS treatment increased the extracellular levels of (A) TNF- $\alpha$ and (B) IL-1 $\beta$, whereas SA3N pretreatment suppressed these LPS-induced increases. ${ }^{* * *} \mathrm{P}<0.001$. IL-1 $\beta$, interleukin- $1 \beta$; LPS, lipopolysaccharide; SA3N, serpin A3N; TNF- $\alpha$, tumor necrosis factor- $\alpha$.

CHOP and $\mathrm{NF}-\kappa \mathrm{B}$, and decreased the expression of I $\mathrm{B} \alpha$, and $\mathrm{SA} 3 \mathrm{~N}$ pretreatment suppressed the changes in expression levels induced by LPS (Fig. 4A-D). The results indicated that the reduction of GrB activity alleviated LPS-induced inflammatory response may occur through the regulation of the $\mathrm{NF}-\kappa \mathrm{B}$ pathway.

\section{Discussion}

GrB is a major constituent of CTL and NK cell granules, and the mechanism of GrB-mediated cell death has been well studied (9). Recent evidence has begun to uncover possible non-cytotoxic roles for $\mathrm{GrB}$ (18). Elevated levels of circulating $\mathrm{GrB}$ are a characteristic feature of a number of inflammatory diseases $(19,20)$. In addition, a previous study reported that $\mathrm{GrB}$ may be involved in LPS-induced toxic shock, which suggested that, not only does GrB promote cell death upon delivery to target cells, but it may also function upon release into the extracellular space (21). However, it remains to be elucidated if $\mathrm{GrB}$ is involved in the development of inflammation. Exploring the role of $\mathrm{GrB}$ in the development of inflammation will provide a new strategy for the treatment of inflammatory diseases.

LPS activates innate immune cells, which leads to the production of pro-inflammatory cytokines (22). It has been reported that citrate is able to modulate LPS-induced monocyte inflammatory responses (23) and that suppression of $\mathrm{NF}-\kappa \mathrm{B}$ signaling in BV-2 microglial cells inhibits LPS-induced inflammatory responses (24). The present study demonstrated that LPS treatment significantly increased the release of inflammatory cytokines TNF- $\alpha$ and IL-1 $\beta$, which indicated that LPS was able to induce the inflammatory response in NK92 cells. The present results also demonstrated that LPS stimulation increased the expression and release of GrB in NK92 cells, which indicated that GrB may be involved in the development of inflammation; however, SA3N pretreatment suppressed this LPS-induced increase. SA3N forms a complex and stable covalent bond with GrB that results in the inhibition of the enzymatic activity of the protease (25). In the present study, treatment with SA3N alone did not change the expression of $\mathrm{GrB}$, whereas pretreatment 
A

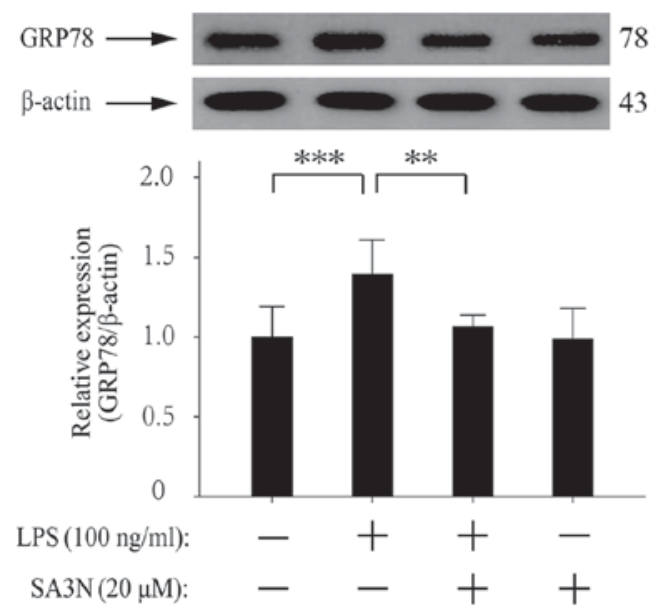

C

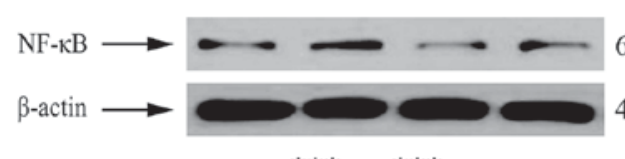

$65 \mathrm{kDa}$
$43 \mathrm{kDa}$
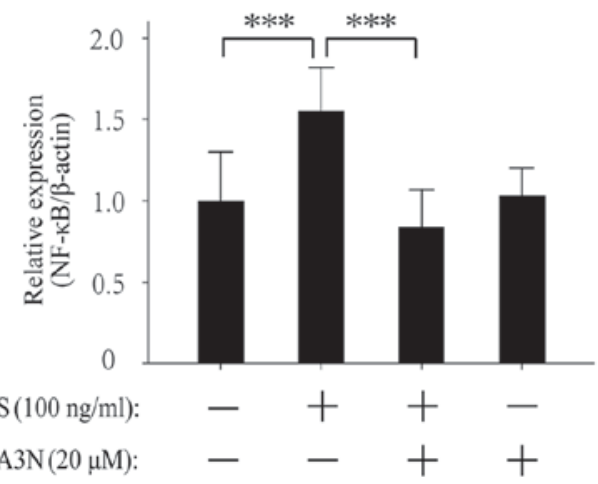

B

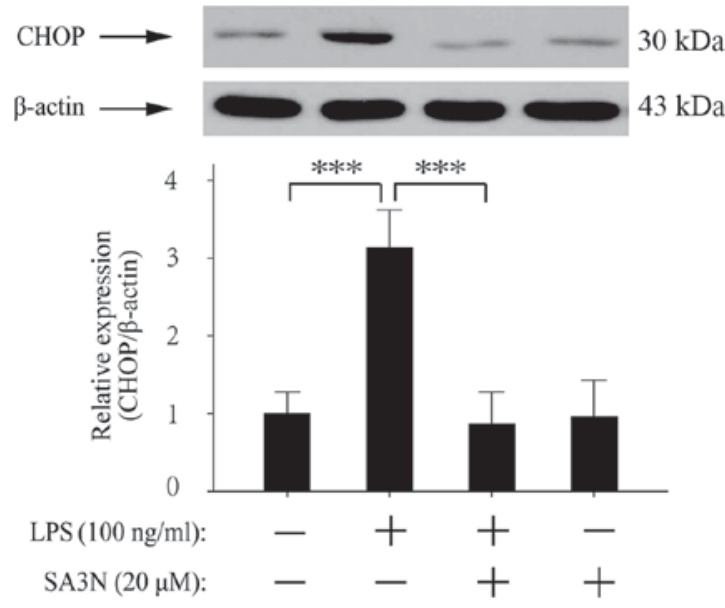

D

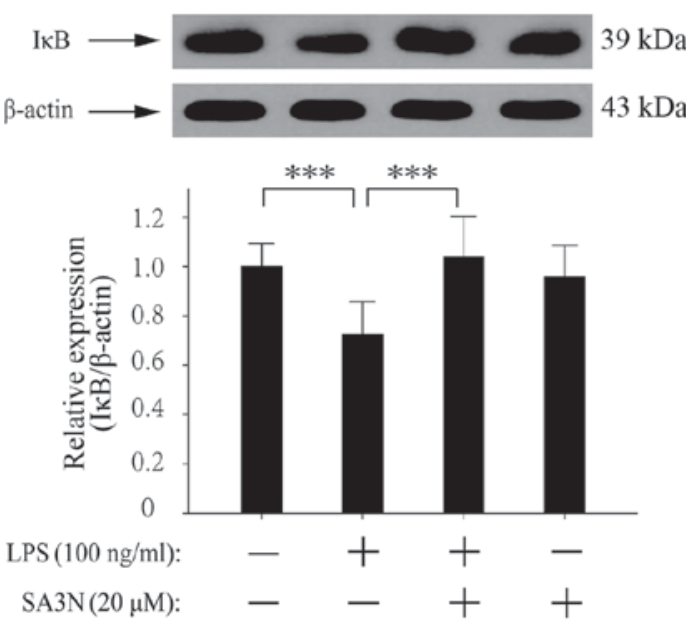

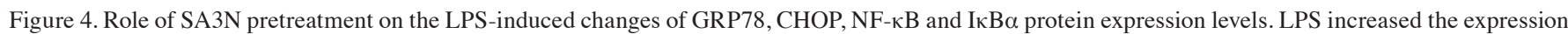
levels of (A) GRP78, (B) CHOP and (C) NF- $\mathrm{kB}$, whereas SA3N pretreatment suppressed the increases induced by LPS. (D) LPS treatment decreased the expression of $\mathrm{I} \kappa \mathrm{B} \alpha$, and SA3N pretreatment suppressed the reduction induced by LPS. ${ }^{* *} \mathrm{P}<0.01$ and ${ }^{* * *} \mathrm{P}<0.001$. CHOP, C/EBP homologous protein; GRP78,

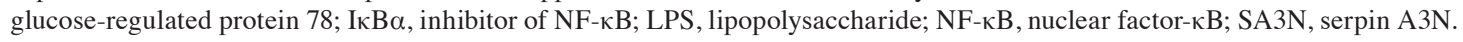

with SA3N prior to LPS stimulation inhibited the expression of GrB in NK92 cells, which suggested that pretreatment with SA3N may block the LPS-induced cytotoxicity mediated by $\mathrm{GrB}$ by suppressing the activity of $\mathrm{GrB}$; this may be the reason that the expression of GrB in LPS + SA3N treated cells was not increased compared with the control group. It was also identified that LPS treatment significantly increased the levels of TNF- $\alpha$ and IL-1 $\beta$, which were also suppressed in cells pretreated with SA3N pretreatment. To elucidate how GrB served its role on LPS-induced inflammation, ER stress was investigated.

ER stress has been reported to be induced by LPS (26). The NF- $\mathrm{B}$ signaling pathway is involved in ER stress (27), and GRP78 and CHOP are markers of ER stress and are involved in the unfolding protein reaction and in the protection mechanism during ER stress (28-30). It has been reported that the increased expression of CHOP during the development of ER stress was inhibited when ER stress was blocked (30). Consistent with these reports, the results of the present study demonstrated that LPS treatment significantly induced the expression levels of GRP78 and CHOP, which were inhibited by
SA3N pretreatment. NF- $\kappa \mathrm{B}$ activation regulates the expression of $>100$ genes involved in diverse cell processes, including cell proliferation, differentiation, apoptosis and the inflammation and immune responses $(31,32)$. A previous study demonstrated that CHOP induced cell inflammatory responses by activating $\mathrm{NF}-\kappa \mathrm{B}$ (33). Results from the present study indicated that LPS treatment induced the expression of $N F-\kappa B$ and decreased the expression of $\mathrm{I} \kappa \mathrm{B} \alpha$, which indicating that LPS induced inflammatory response may be through initiating ER stress. However, inhibition of GrB activity suppressed the changes of NF- $\kappa \mathrm{B}$ and $\mathrm{I} \kappa \mathrm{B} \alpha$ expression levels induced by LPS. Thus, it was hypothesized that inhibition of GrB activity may have suppressed ER stress by blocking the NF- $\kappa \mathrm{B}$ pathway, which may indicate that inhibition of GrB activity blocked the development of inflammation. In addition, it has been reported that TNF- $\alpha$ mediated the activation of NF- $\kappa \mathrm{B}$ in various disease processes, including inflammation and cell apoptosis (34). In the present study, inhibition of GrB activity blocked the exocytosis of TNF- $\alpha$, and it is therefore suggested that the reduction of TNF- $\alpha$ levels may be the key point that blocked the activation of the $\mathrm{NF}-\kappa \mathrm{B}$ pathway. 
SA3N is the only known GrB activity inhibitor that is secreted extracellularly (35). It has been previously reported that SA3N attenuates GrB-mediated decorin cleavage and rupture in a mouse model of aortic aneurysm (15) and that $\mathrm{SA} 3 \mathrm{~N}$ induces neuroprotection in vitro and in vivo, which has been reported to be a potentially novel therapeutic approach for inflammation-mediated neurodegenerative diseases such as multiple sclerosis (23). However, SA3N is not a GrB specific inhibitor. It has been reported that SA3N may accelerate the wound healing process by inhibiting the activity of the serine proteases cathepsin G and GrB that are associated with inflammation, as well as matrix metalloproteinase 9 that is associated with extracellular matrix breakdown and remodeling $(13,15,36)$. In addition, SA3N also inhibits $\mathrm{T}$ cell-derived leukocyte elastase, which helps attenuate neuropathic pain (14). Taken together, SA3N as a $\mathrm{GrB}$ activity inhibitor may serve various protective roles by acting on different targets. Thus, it was suggested that SA3N may serve its protective role on LPS-induced inflammatory response as the result of the concurrent effects of various factors and mechanisms.

In conclusion, the results of the present study indicated that GrB may be a potential pro-inflammatory factor that is induced by LPS, and the inhibition of GrB activity may block LPS-induced inflammatory response. It is hypothesized that GrB may be involved in the development of inflammation through regulation of the NF- $\kappa \mathrm{B}$ pathway, mediated by TNF- $\alpha$. Therefore, GrB has potential as a therapeutic agent for inflammatory diseases. However, the connection between GrB and TNF- $\alpha$, and the molecular mechanism of their interaction requires further study.

\section{Acknowledgements}

Not applicable.

\section{Funding}

This study was funded by The National Natural Science Foundation of China (grant no. 81202331).

\section{Availability of data and material}

All data generated or analyzed during this study are included in this published article.

\section{Authors' contributions}

JT and LW were responsible for the study concept and design. LW and SJ performed the western blot analysis. LX and LC performed the ELISA analysis. YZ performed the MTT assay. JT and LW assisted with data analysis and interpretation of results. LW drafted the manuscript. JT and LW provided critical revision of the manuscript for important intellectual content. All authors critically reviewed the content and approved final version for publication.

\section{Ethics approval and consent to participate}

Not applicable.

\section{Consent for publication}

Not applicable.

\section{Competing interests}

The authors declare that they have no competing interests.

\section{References}

1. Bladergroen BA, Meijer CJ, ten Berge RL, Hack CE, Muris JJ, Dukers DF, Chott A, Kazama Y, Oudejans JJ, Berkum O, et al: Expression of the granzyme B inhibitor, protease inhibitor 9, by tumor cells in patients with non-Hodgkin and Hodgkin lymphoma: A novel protective mechanism for tumor cells to circumvent the immune system? Blood 99: 232-237, 2002.

2. Thomas DA, Scorrano L, Putcha GV, Korsmeyer SJ and Ley TJ: Granzyme B can cause mitochondrial depolarization and cell death in the absence of BID, BAX, and BAK. Proc Natl Acad Sci USA 98: 14985-14990, 2001.

3. Alimonti JB, Shi L, Baijal PK and Greenberg AH: Granzyme B induces BID-mediated cytochrome $\mathrm{c}$ release and mitochondrial permeability transition. J Biol Chem 276: 6974-6982, 2001.

4. Mattila JT, Maiello P, Sun T, Via LE and Flynn JL: Granzyme B-expressing neutrophils correlate with bacterial load in granulomas from Mycobacterium tuberculosis-infected cynomolgus macaques. Cell Microbiol 17: 1085-1097, 2015.

5. Classen CF, Bird PI and Debatin KM: Modulation of the granzyme B inhibitor proteinase inhibitor 9 (PI-9) by activation of lymphocytes and monocytes in vitro and by Epstein-Barr virus and bacterial infection. Clin Exp Immunol 143: 534-542, 2006.

6. Rousalova I and Krepela E: Granzyme B-induced apoptosis in cancer cells and its regulation (review). Int J Oncol 37: 1361-1378, 2010.

7. Lord SJ, Rajotte RV, Korbutt GS and Bleackley RC: Granzyme B: A natural born killer. Immunol Rev 193: 31-38, 2003.

8. Yin XM: Bid, a BH3-only multi-functional molecule, is at the cross road of life and death. Gene 369: 7-19, 2006.

9. Afonina IS, Cullen SP and Martin SJ: Cytotoxic and non-cytotoxic roles of the CTL/NK protease granzyme B. Immunol Rev 235: 105-116, 2010.

10. Froelich CJ, Pardo J and Simon MM: Granule-associated serine proteases: Granzymes might not just be killer proteases. Trends in Immunol 30: 117-123, 2009.

11. Afonina IS, Tynan GA, Logue SE, Cullen SP, Bots M, Lüthi AU, Reeves EP, McElvaney NG, Medema JP, Lavelle EC and Martin SJ: Granzyme B-dependent proteolysis acts as a switch to enhance the proinflammatory activity of IL-1 $\alpha$. Mol Cell 44: 265-278, 2011.

12. Kim HJ, Jeong JS, Kim SR, Park SY, Chae HJ and Lee YC: Inhibition of endoplasmic reticulum stress alleviates lipopolysaccharide-induced lung inflammation through modulation of NF-кB/HIF-1 $\alpha$ signaling pathway. Sci Rep 3: 1142, 2013.

13. Tjondrokoesoemo A, Schips T, Kanisicak O, Sargent MA and Molkentin JD: Genetic overexpression of Serpina3n attenuates muscular dystrophy in mice. Hum Mol Genet 25: 1192-1202, 2016.

14. Vicuña L, Strochlic DE, Latremoliere A, Bali KK, Simonetti M, Husainie D, Prokosch S, Riva P, Griffin RS, Njoo C, et al: The serine protease inhibitor Serpin A3N attenuates neuropathic pain by inhibiting T cell-derived leukocyte elastase. Nat Med 21: 518-523, 2015.

15. Ang LS, Boivin WA, Williams SJ, Zhao H, Abraham T, Carmine-Simmen K, McManus BM, Bleackley RC and Granville DJ: Serpina3n attenuates granzyme B-mediated decorin cleavage and rupture in a murine model of aortic aneurysm. Cell Death Dis 2: e209, 2011.

16. Haile Y, Carmine-Simmen K, Olechowski C, Kerr B Bleackley RC and Giuliani F: Granzyme B-inhibitor serpina3n induces neuroprotection in vitro and in vivo 12: 157, 2015.

17. Duan L, Zhang X, Panpan YU, Feng YU, Liu W and Song N: Effects of cholecystokinin-octopeptide on endoplasmic reticulum stress induced by LPS in mouse monocyte RAW264.7 cells. Journal of Shandong University 53: 16-20, 2015.

18. Afonina IS, Cullen SP and Martin SJ: Cytotoxic and non-cytotoxic roles of the CTL/NK protease granzyme B. Immunol Rev 235: 105-116, 2010. 
19. Tak PP, Kummer JA, Hack CE, Daha MR, Smeets TJ, Erkelens GW, Meinders AE, Kluin PM and Breedveld FC: Granzyme-positive cytotoxic cells are specifically increased in early rheumatoid synovial tissue. Arthritis Rheum 37: 1735-1743, 1994.

20. Goldbach-Mansky R, Suson S, Wesley R, Hack CE, El-Gabalawy HS and Tak PP: Raised granzyme B levels are associated with erosions in patients with early rheumatoid factor positive rheumatoid arthritis. Ann Rheum Dis 64: 715-721, 2005.

21. Metkar SS, Menaa C,Pardo J, Wang B, Wallich R, Freudenberg M Kim S, Raja SM, Shi L, Simon MM and Froelich CJ: Human and mouse granzyme A induce a proinflammatory cytokine response. Immunity 29: 720-733, 2008.

22. Rossol M, Heine H, Meusch U, Quandt D, Klein C, Sweet MJ and Hauschildt S: LPS-induced cytokine production in human monocytes and macrophages. Crit Rev Immunol 31: 379-446, 2011.

23. Ashbrook MJ, McDonough KL, Pituch JJ, Christopherson PL, Cornell TT, Selewski DT, Shanley TP and Blatt NB: Citrate modulates lipopolysaccharide-induced monocyte inflammatory responses. Clin Exp Immunol. 180: 520-530, 2015.

24. Kwon SH,MaSX,Hong SI,Lee SY and Jang CG: Lonicera japonica THUNB. Extract Inhibits Lipopolysaccharide-Stimulated Inflammatory Responses by Suppressing NF- $\kappa \mathrm{B}$ Signaling in BV-2 Microglial Cells. J Med Food 18: 762-775, 2015

25. Haile Y,Carmine-Simmen K, Olechowski C, Kerr B, Bleackley RC and Giuliani F: Granzyme B-inhibitor serpina3n induces neuroprotection in vitro and in vivo. J Neuroinflammation 12: 157, 2015.

26. Liu H, Yin JJ, Cao MM, Liu GD, Su Y and Li YB: Endoplasmic reticulum stress induced by lipopolysaccharide is involved in the association between inflammation and autophagy in INS-1 cells. Mol Med Rep 16: 5787-5792, 2017.

27. Prell T, Lautenschläger J, Weidemann L, Ruhmer J, Witte OW and Grosskreutz J: Endoplasmic reticulum stress is accompanied by activation of NF- $\mathrm{BB}$ in amyotrophic lateral sclerosis J Neuroimmunol 270: 29-36, 2014.
28. Liu H, Qian J, Wang F, Sun X, Xu X, Xu W, Zhang X and Zhang X: Expression of two endoplasmic reticulum stress markers, GRP78 and GADD153, in rat retinal detachment model and its implication. Eye (Lond) 24: 137-144, 2010.

29. Lee AS: The ER chaperone and signaling regulator GRP78/BiP as a monitor of endoplasmic reticulum stress. Methods 35: 373-381, 2005.

30. Chen G, Li X, Huang M, Li M, Zhou X, Li Y and Bai J: Thioredoxin-1 increases survival in sepsis by inflammatory response through suppressing endoplasmic reticulum stress. Shock 46: 67-74, 2016

31. Lin WC, Chuang YC, Chang YS, Lai MD, Teng YN, Su IJ, Wang CC, Lee KH and Hung JH: Endoplasmic reticulum stress stimulates p53 expression through $\mathrm{NF}-\kappa \mathrm{B}$ activation. PLoS One 7: e39120, 2012

32. Ghosh S and Karin M: Missing pieces in the NF-kappaB puzzle. Cell 109 (Suppl): S81-S96, 2002.

33. Willy JA, Young SK, Stevens JL, Masuoka HC and Wek RC: $\mathrm{CHOP}$ links endoplasmic reticulum stress to NF- $\kappa \mathrm{B}$ activation in the pathogenesis of nonalcoholic steatohepatitis. Mol Biol Cell 26: 2190-2204, 2015.

34. Legler DF, Micheau O, Doucey MA, Tschopp J and Bron C: Recruitment of TNF Receptor 1 to Lipid Rafts Is Essential for TNFalpha-Mediated NF-kappaB Activation. Immunity 18: 655-664, 2003.

35. Palacios MM and Bleackley C: Characterization of Critical Residues of the Granzyme B Inhibitor, Serpina3n (50.43). J Immunol 182: 43-50, 2009.

36. Han YP, Yan C and Garner WL: Proteolytic activation of matrix metalloproteinase-9 in skin wound healing is inhibited by alpha-1-Antichymotrypsin. J Invest Dermatol 128: 2334-2342, 2008. 